\title{
Effects of Nitrogen and Potassium Fertilizers on Blueberry Fruit's
}

\section{Quality}

\author{
Bo-lei Jiao", Yuan Luo ${ }^{1}$, Bo-wen Wang ${ }^{1}$, Kai-li Chen ${ }^{1}$,Yan-hong Li ${ }^{2}$, Xun \\ Wang $^{1, a}$
}

${ }^{1}$ Sichuan Agricultural University, Wenjiang, Chengdu, China 611130

${ }^{2}$ Luzhou Hongke Agricultural Co. Ltd, Naxi, Luzhou, China 646300

a35744023@qq.com

Keywords: Blueberry, Nitrogen, Potassium, Fruit quality.

\begin{abstract}
The effects of nitrogen (N) and potassium (K) fertilizers on fruit qualities of blueberry 'Legacy' were studied. A field experiment was conducted using randomized block design. The results showed that the fruit weight and total soluble solids content of blueberry were significantly increased by fertilizations. The water content of Treatment 3(T3), T5 and T6 declined by 9.45\%, $10.67 \%$ and $13.44 \%$ respectively compared with control. In general, T3 and T6 showed higher levels of vitamin C content. T3 was the best treatment in terms of soluble sugar content. The results of double factor variance analysis showed that he optimum fertilization combination was $45 \mathrm{~g} /$ tree of $\mathrm{N}$ and $30 \mathrm{~g} /$ tree of $\mathrm{K}_{2} \mathrm{O}$.
\end{abstract}

\section{Introduction}

Blueberry (Vaccinium spp.) is berry fruit, small-scale and dark purple. It is rich in nutrient substances, especially anthocyanin [1]. Blueberry has high economic value. It has attracted increasing attention in recent years as the third generation of fruits [2], and its industry is developing rapidly. Up to 2015 , there were more than 77,000 ha of cultivated blueberry be grown worldwide, which is expected to increase by another $46 \%$ on its yield over the next five years [3]. In China, many achievements have been made in the study of blueberry cultivation techniques [4].

Blueberry is a kind of oligotrophic plants. Its response to fertilizer is very sensitive. Inadequate or excessive fertilizing would lead to slow growth, lower yield, plant damage and even death [5]. Blueberry is an ammonium (N)-philic plant, which indicates that blueberry has a great absorption ability of ammonium nitrogen [6]. The application of nitrogen fertilizer significantly increased the content of effective ingredients such as soluble sugar, fruit anthocyanin, flavonoid and total phenolic [7]. Improper nitrogen fertilization would lead to weaker growth and the elimination of fruit quality [8]. Potassium $(\mathrm{K})$ is required by all plants. Previous studies showed that potassium fertilizer application can increase blueberry fruit yields, accelerate the ripeness, and improve tree resistance to cold [9]. Excessive potassium fertilization caused yield reduction and smaller fruits $[10,11]$.

\section{Materials and methods}

Materials. A total of 63 Northern highbush "Legacy" trees grown for 3 years were used. The experiment site was in Qionglai, Sichuan, where altitude is $1350 \mathrm{~m}$. The average temperature is 
$16.3^{\circ} \mathrm{C}$, and the annual accumulated temperature above $10^{\circ} \mathrm{C}$ is 4500 to 5500 approximately. The average annual precipitation is $1100 \mathrm{~mm}$, annual sunshine duration is $1107.9 \mathrm{~h}$, and frost-free season is $285 \mathrm{~d}$. Soil type is mountain yellow-brown soil [12].

Fertilizers application. The fertilizers in our experiment are ammonium sulfate ( $\mathrm{N} 20 \%$ ) and potassium sulfate $\left(\mathrm{K}_{2} \mathrm{O} 50 \%\right)$. Fertilizers application was showed in Table 1 . The nitrogen fertilizer has three levels and the potassium fertilizer has two levels. Fertilizers combinations contain CK(No fertilization), T1 (N1, K1), T2 (N2, K1), T3 (N3, K1), T4 (N1, K2), T5 (N2, K2), T6 (N3, K2). Tested trees were divided into 7 treatments by the randomized blocks design with three repetition per treatment and three trees per repetition. The fertilizer were fertilized around the crown shadow by hole fertilization in a week before germination, combined with irrigation.

Table 1 Levels of nitrogen and potassium fertilizer application

\begin{tabular}{ccc}
\hline Level & $\mathbf{N}(\mathbf{g} /$ tree $)$ & $\mathbf{K}_{\mathbf{2}} \mathbf{O}(\mathbf{g} /$ tree $)$ \\
\hline $\mathbf{1}$ & 15 & 20 \\
$\mathbf{2}$ & 30 & 30 \\
$\mathbf{3}$ & 45 & $/$
\end{tabular}

Determination of fruit qualities. The following indexes were determined: (1) Fruit weight was expressed as: fruit weight $(\mathrm{g})=\mathrm{W} / 10, \mathrm{~W}$ was the ten-fruit weighted. (2) Fruit shape index was the ratio of vertical diameter and horizontal diameter: fruit shape index $=$ L1/L2, L1 was the vertical diameter, L2 was the horizontal diameter. (3) The TSS content (\%) of the fresh blueberry was measured with a portable refractometer. Zero adjustment was always carried out prior to use. (4) Water content $(\%)$ was determined as: water content $(\%)=(\mathrm{W} 1-\mathrm{W} 2) / 10 \mathrm{~W}^{*} 100$, W1 was the weight of 10 fruits at harvest time and W2 was the weight of 10 fruits dried to constant weight at $65^{\circ} \mathrm{C}$. (5) Soluble sugar was determined by anthrone and sulphuric acid colorimetry[13]. (6) Vitamin C was determined by Xylene - 2,6 - dichlorophenolindophenol colorimetry [14].

\section{Results}

Effects of different fertilizations on fruits weight and shape index. Trees treated with fertilization showed significantly increased on fruits weight compared with control (Fig.1), except for T1 $(\mathrm{p}<0.05)$. The fruit weight of T6 is $2.46 \mathrm{~g}$, which is the best treatment. Fruit shape index of blueberry in all treatments were not significantly different compared with control. Applying level 2 (30g/tree) and level 3 (45g/tree) of Nitrogen fertilizer combined with potassium fertilizer increased the fruit weight significantly $(\mathrm{p}<0.05)$.

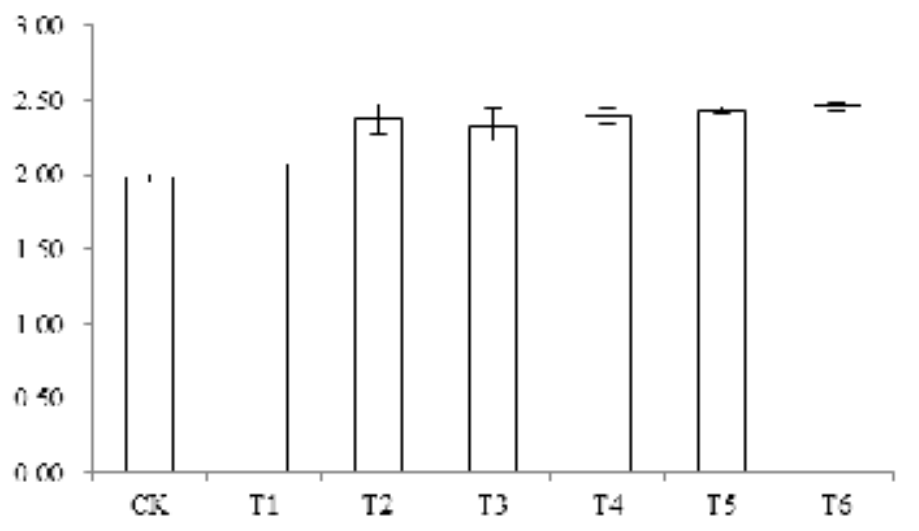

Fig. 1 Effect of various fertilization treatments on fruits weight 
Table 2 Effects of various fertilization treatments on horizontal and vertical diameters and shape index of blueberry

\begin{tabular}{cccc}
\hline $\begin{array}{c}\text { No. } \\
\text { treatment }\end{array}$ & $\begin{array}{c}\text { Horizontal diameter } \\
(\mathbf{m m})\end{array}$ & $\begin{array}{c}\text { Vertical diameter } \\
(\mathbf{m m})\end{array}$ & Shape index \\
\hline CK & $16.95 \pm 0.41 \mathrm{~b}$ & $12.82 \pm 0.14 \mathrm{ab}$ & $0.76 \pm 0.02 \mathrm{a}$ \\
T1 & $16.7 \pm 0.72 \mathrm{~b}$ & $12.44 \pm 0.77 \mathrm{~b}$ & $0.74 \pm 0.02 \mathrm{a}$ \\
T2 & $17.47 \pm 0.26 \mathrm{ab}$ & $13.58 \pm 0.40 \mathrm{a}$ & $0.78 \pm 0.03 \mathrm{a}$ \\
T3 & $17.48 \pm 0.54 \mathrm{ab}$ & $13.03 \pm 0.13 \mathrm{ab}$ & $0.75 \pm 0.02 \mathrm{a}$ \\
T4 & $18.25 \pm 0.51 \mathrm{a}$ & $13.26 \pm 0.89 \mathrm{ab}$ & $0.73 \pm 0.03 \mathrm{a}$ \\
T5 & $17.44 \pm 0.47 \mathrm{ab}$ & $12.93 \pm 0.49 \mathrm{ab}$ & $0.74 \pm 0.03 \mathrm{a}$ \\
T6 & $17.44 \pm 0.22 \mathrm{ab}$ & $13.24 \pm 0.49 \mathrm{ab}$ & $0.76 \pm 0.03 \mathrm{a}$ \\
\hline
\end{tabular}

For the same index, statistical significant difference at $p<0.05$ was expressed by using different letters after each value.

TSS content. Inadequate fertilization had little effect on the accumulation of TSS. The rank of all treatments on TSS content was T3>T6>T2>T4>T5>T1>CK. The least TSS content occurred in CK, with all treatments significantly better than this $(\mathrm{p}<0.05)$ except for T1. As shown in Fig.2, nitrogen fertilizer application of level $2(30 \mathrm{~g} /$ tree $)$ and level $3(45 \mathrm{~g} /$ tree $)$ combined with potassium fertilizer application have significantly higher TSS content than control $(\mathrm{p}<0.05)$.

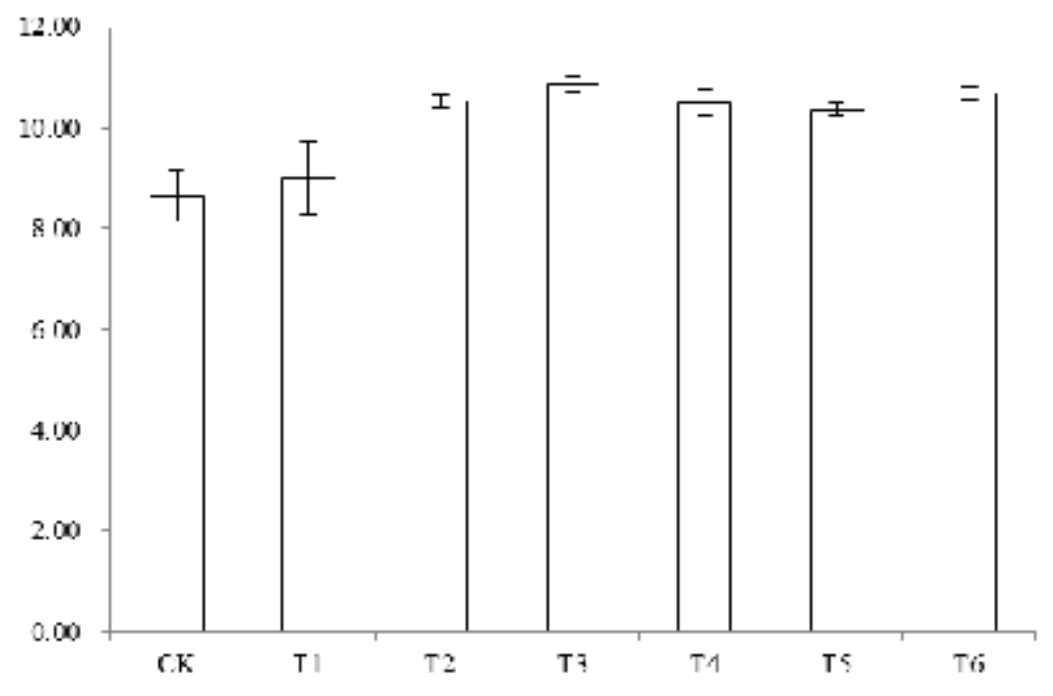

Fig. 2 Effect of various fertilization treatments on TSS

Water content. Treatments T1 maintained water content at higher levels than the other treatments. Water content of T3, T5 and T6 were 78.99\%, 77.92\%, 75.51\% respectively, while CK was $79.61 \%$. The coefficient of dispersion revealed little difference in the water content of treatment T6, and the other treatments also achieved great results for their values were less than 0.2. 


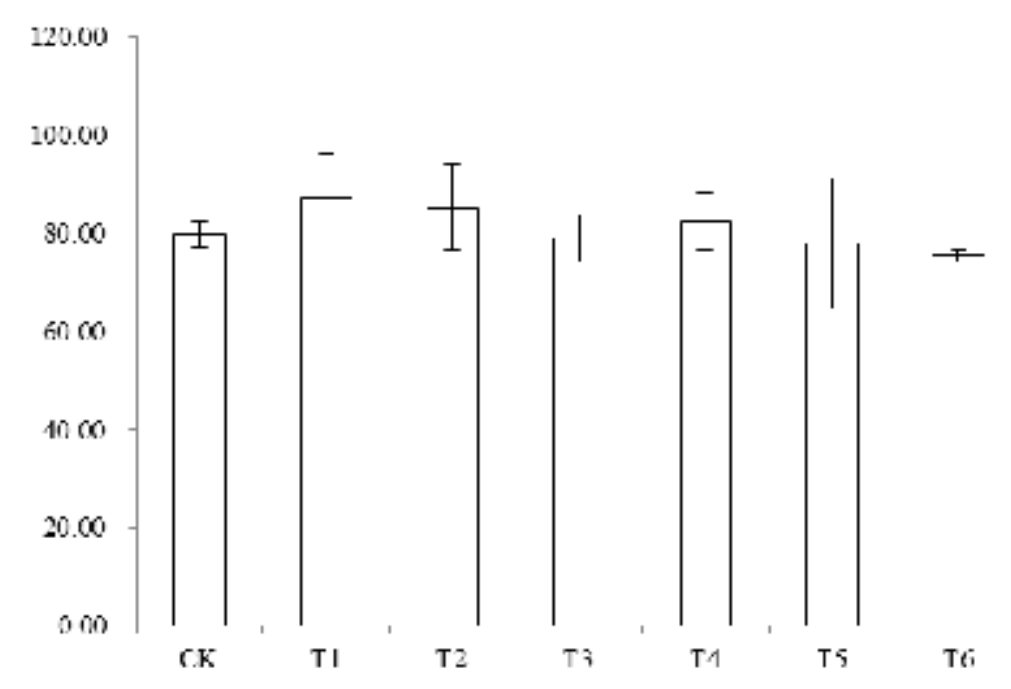

Fig. 3 Effect of various fertilization treatments on water

Soluble sugar. As shown in Fig.4, the treatment of great soluble sugar content was T3 (11.55\%), which was significantly better than CK $(\mathrm{p}<0.05)$. The next great content of soluble sugar occurred in T6 (10.60\%) and T2 (8.71\%). According to Table 4 and 5, nitrogen fertilizer application of level 3 (45g/tree) had significantly more beneficial effects than the others, while potassium fertilizer application had little effects on the accumulation of soluble sugar.

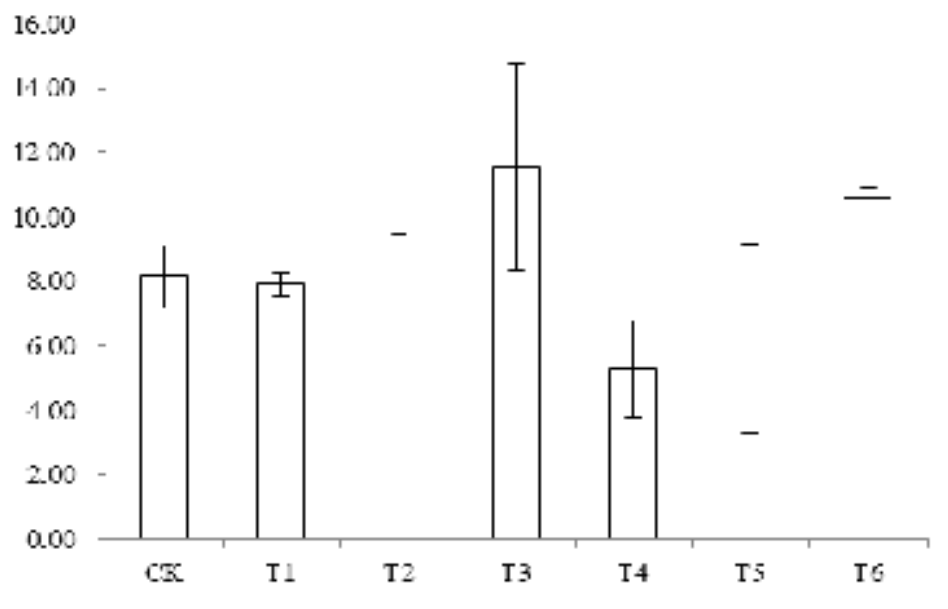

Fig. 4 Effect of various fertilization treatments on soluble sugar

Vitamin C. Comparing all treatments on vitamin $\mathrm{C}$ contents indicated that the great treatments were T3 (1.78 mg/100g FW) and T6 (1.77 mg/100g FW) (Fig.5). Nitrogen fertilizer application of level $2(30 \mathrm{~g} /$ tree $)$ and level $3(45 \mathrm{~g} /$ tree $)$ combined with potassium fertilizer application showed higher contents of vitamin $\mathrm{C}$ than the control. 


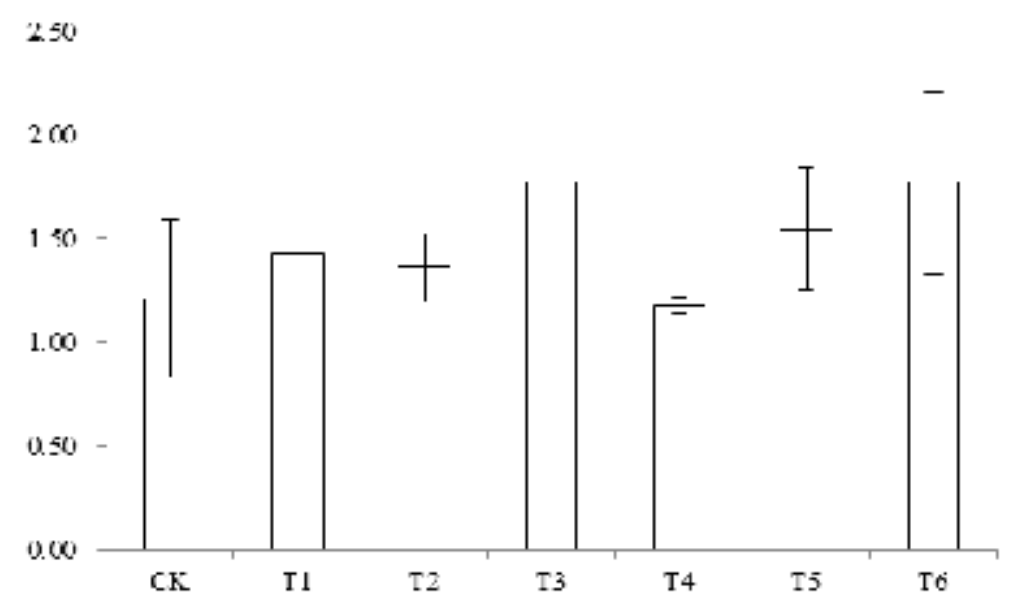

Fig. 5 Effect of various fertilization treatments on vitamin C

\section{Discussion}

Fertilizers with different N, P, K contents have different effects on blueberry fruit weight [15]. From our results, increasing nitrogen and potassium fertilizer application significantly increased the single fruit weight. Due to the low content of nitrogen and potassium in soil and the low fertilization level of our experiment, the accurate trend need to be ascertained by more tests with higher fertilization level setting. In T3, T5 and T6 treatment, water contents of fruits were relatively low, which was beneficial to extend shelf life [16]. Our results indicated that higher levels of fertilizer application are effective in maintaining fruit water content in lower levels. Blueberries are sensitive to fertilization [6], which was reconfirmed by our research results. Among all the treatments, T3 and T6 maximally enhanced the content of TSS and soluble sugar compared with the control. In this study, we found that the optimum fertilization combination was $\mathrm{N}(45 \mathrm{~g} /$ tree) and $\mathrm{K}_{2} \mathrm{O}(30 \mathrm{~g} /$ tree $)$ via double factor variance analysis.

\section{References}

[1] Hong-da Zhang, Yun-hui Huang, Ru-huai Miu. Seed plant systematics [M]. Beijing: Science Press, 2004A

[2] Ya-dong Li, Hui-tie Jiang, Zhi-dong Zhang, Lin Wu. Prospect of industrialization development of Blueberry in China [J]. Social Science Journal of Shenyang Agricultural University, 2001, 3 (1): 39-42.

[3] Min-kai Ge. Effect of fertilization on fruit yield and quality of rabbiteye blueberry [M]. Guiyang: Guizhou University, 20154 Min-kai Ge. Effect of fertilization on fruit yield and quality of rabbiteye blueberry [M]. Guiyang: Guizhou University, 2015

[4] Feng-zhang Wu, He-xin Wang, Ying-min Chen, et al. Progress of studies on the physiology and ecology of blueberry in China [J]. Northern Horticulture, 2006 (3): 48-49.

[5] Austin M E, Brightwell W T. Effect of fertilizer applications on yield of rabbiteye blueberries.[J]. Journal American Society for Horticultural Science, 1977, 102:36-39.

[6] Fanqiang Meng. Management and Cultivation Techniques of economic forest blueberry [J]. Jilin Vegetables, 2014, (5): 46-47.

[7] Wei Pang. Effect of soil management and fertilization on growth, yield and fruit quality of blueberry [M] Beijing: Beijing Forestry University, 2012 
[8] Ballinger, W.E., and Kushman. Factors affecting the mineral element content of leaves and fruit of Wolcott blueberry [J]. Proc Amer Soc Hort Sci,1966 88(1):325-330

[9] Ya-dong Li, Lin Wu. Effects of application of N, NP and NPK fertilizers on growth, yield and leaf element content of blueberry [J]. Jilin Agricultural Sciences, 1997, (3): 69-72.

[10] Jie-nan Wei. Studies on the effect of nitrogen, phosphorus and potassium and formulated fertilizer application of blueberry [M] Changchun, Jilin Agricultural University, 2007

[11] Na Chen. Effect of iron and potassium nutrition on growth and physiological characteristics of blueberry plantlets [M] Dalian University of Technology, 2010

[12] Xun Wang, Ren-chong Yin, Bo-lei Jiao. The development and prospect of blueberry industry in Mount Nanbao, Qionglai [J]. Sichuan Agricultural Science and Technology, 2016 (12): 42-44.

[13] Bao-zhang Bai. Plant Physiology (Volume II : experimental tutorial) [M]. Beijing: Chinese Agricultural Science and Technology Press, 1996.

[14] Feng-xia Wang, Yu-qin Huang, Tian-zhu Xie. Comparison of methods for determination of vitamin C content in fruits and vegetables [J] Deciduous Fruits, 2013, 45 (2): 8-11.

[15] Yu-jiao Luo, The response to soil nutrient status and fertilization of blueberries [M] Nanchang: Jiangxi Agricultural University, 2016.

[16] Chun-miao Ye, Recent advances in storage technology of blueberries [J] Agricultural Science\&Technology and Equipment, 2015 (11): 45-46. 